\title{
Dissecting the Dissection
}

\section{Towards More Comprehensive Decision-Making Methodology for Thoracic Aortic Disease}

\author{
Hisham M.F. Sherif, MD, FACS, FICS, FACC, FAHA \\ Department of Cardiac Surgery, Christiana Hospital, Christiana Care Health System, Newark, Delaware, USA
}

\begin{abstract}
Aortic dissection remains one of the most devastating diseases. Current practice guidelines provide diagnostic and therapeutic interventions based primarily on the aortic diameter. The level of evidence supporting these recommendations is Level C or "Expert Opinion" Since aortic dissection is a catastrophic structural failure, its investigation along the guidelines of accident investigation may offer a useful alternative, utilizing process mapping and root-cause analysis methodology. Since the objective of practice guidelines is to address the risk of serious events, on the utilization of a probabilistic predictive modeling methodology, using bioinformatics tools, may offer a more comprehensive risk assessment.

Copyright @ 2015 Science International Corp.
\end{abstract}

\section{Key Words}

Aortic - Dissection - Bioinformatics - Predictive modeling • Clinical guidelines

"In these matters, the only certainty is that nothing is certain" - Pliny the Elder

\section{Introduction}

Thoracic aortic dissection remains a significant health risk. Affecting about 3-4 in 100,000 or nearly 30 cases per million per year, aortic dissection is always associated with a high risk of mortality and morbidity [1].

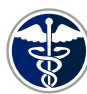

Fax +1 2037853552

E-Mail: aorta@scienceinternational.org

http://aorta.scienceinternational.org

\author{
(c) 2015 AORTA \\ Published by Science International Corp. \\ ISSN 2325-4637 \\ Accessible online at: \\ http://aorta.scienceinternational.org
}

In light of these risks, the professional organizations involved in the regulation of cardiovascular disease care have emphasized the importance of early intervention in high-risk situations, in an effort to reduce or mitigate the adverse effects of such a devastating condition. The current clinical practice guidelines, issued jointly by these organizations in 2010, attempt to establish some basic predictive rules for patients perceived to be at an elevated risk for aortic dissection. However, the high-level (Class I) recommendations in these guidelines are based on low-level evidence (Level C or expert opinion) in most cases [2]. Furthermore, the guidelines are primarily based on a single criterion: namely, the aortic diameter. This threshold for intervention is presented as a raw data unit or as indexed to the body surface area. The language of the introductory part of the guidelines seems to suggest that that aortic dilatation up to or beyond a specific diameter is associated with a higher risk for aortic dissection. This may be related to the description of the "Dissecting Aneurysm" in the literature. Notably, data from the international Registry of Aortic Dissection (IRAD) demonstrate that almost half $(\sim 46 \%)$ of cases dissect with an aortic diameter less than $5.5 \mathrm{~cm}$ [3].

\section{Historical Background}

The first recorded report of an acute aortic dissection was on October 1760, when the British monarch

* Corresponding Author:

Hisham M.F. Sherif, MD, FACS, FICS, FACC, FAHA

Department of Cardiac Surgery

Christiana Hospital

Christiana Care Health System, Newark, Delaware 19718, USA

Tel. +1302 733 1980, Fax. +1302 733 1986, E-Mail: hsherif@christianacare.org 


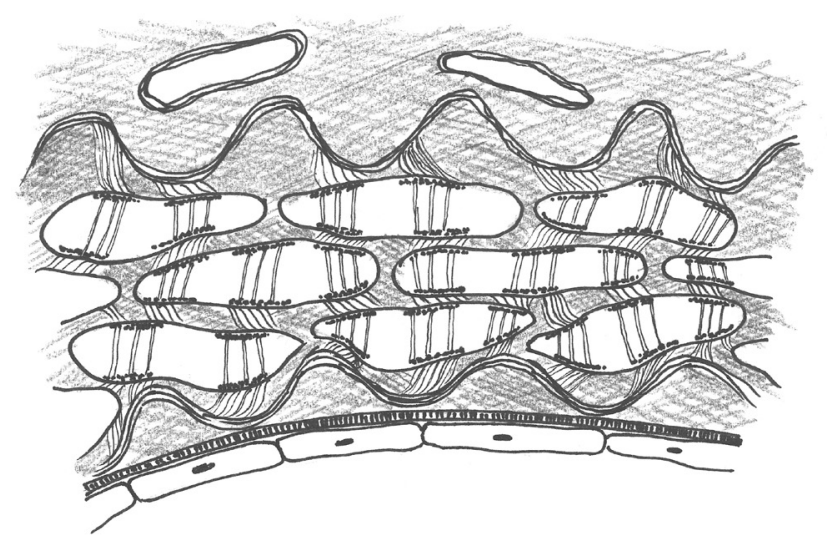

Figure 1. Schematic representing the different components and layers of the aortic walland the "elastic skeleton" of fibrillin, actin and elastin within the wall responsible for absorbing the energy load is depicted.

King George II collapsed in the bathroom shortly after having his usual morning chocolate drink. Resuscitation attempts by Mr. Andrews, surgeon to the royal household, failed. Dr. Nicolls, physician to the late king, was called upon for "embalming" the body. In his postmortem examination, he noted a "transverse fissure in the ascending aorta measuring about $3.75 \mathrm{~cm}$. In 1802, Maunoir described blood "dissecting throughout the circumference of the aorta". In 1809, a necropsy report by Burns on a 56 year old male again demonstrated a tear $1.25-\mathrm{cm}$ long in the ascending aorta, with an "aneurysmal sac" described as located "between the proper and cellular layers" (most likely referring to the false lumen). Similar findings were reported by Hodgson in 1815 in a 70-year-old female [4].

The first clinician to coin the term "anevrisme disséquant" or "dissecting aneurysm" was Laennec in 1826 [5]. This term may have influenced an assumption that all dissections are the result of dilatation of the aorta up to or beyond a critical diameter $(6.0 \mathrm{~cm})$;

\section{Structural and Functional Considerations}

The aorta is composed of multiple layers arranged in a concentric pattern, the innermost being the single-layer endothelium, resting against the basement membrane. Beyond that, the tunica media layer comprises a complex array of extracellular matrix components: collagen fibers arranged in longitudinal, circumferential and radial fashion, describing a helical pattern; elastin fibers arranged in criss-cross patterns starting at the basement membrane and enveloping the vascular smooth muscle cells with intimate contact. Elastin fibres describe two distinct circular layers: the internal and external elastic lamellae at the inner and outer boundaries of the tunica media. This layer is responsible for both structural integrity (by virtue of its "stiff" or "rigid" collagen component which can sustain considerable energy loads without stretching) as well as elasticity property of the vessel (because of its elastin content, which deforms easily in response to mechanical stress and quickly resumes its original shape as the stress decreases). In addition, there is a "fibrous skeleton" within the vascular wall, incorporating the smooth muscle cells, and is crucial for transmission of the energy load across the thickness of the wall (Figure 1). The structure, composition and configuration of the tunica media components is dictated and regulated by numerous factors, including genetic, transcriptional, enzymatic, metabolic, hormonal and humoral mechanisms that have a highly complex and interdependent pattern of influence $[6,7]$. Although the vascular smooth muscle cells play a central role [8] in the regulation of the extracellular matrix and its components, these cells are themselves under the influence of numerous other factors derived from the vascular wall as well systemic components $[9,10]$.

One factor exerting a major influence on the vascular wall homeostasis is the process of mechano-transduction, where the cyclic changes in the intraluminal pressure with each heartbeat cause a cyclic stretch of the aortic wall. This process causes an energy load to be transmitted across the entire thickness of the aortic wall, mediated through the endothelial layers at first but more significantly through the tunica media and its elastin-derived components. The elastic property of the aortic wall, allowing it to deform then resume its original dimensions, combined with the structural strength of its predominately collagen-containing extracellular matrix, are crucial for preserving the integrity of the vascular wall in the face of the force applied to it with each pulsation. Unlike other rigid materials, the aortic wall's extensibility is not proportional to the force applied. Rather, the modulus of elasticity (the tangential slope of the stress-strain curve) changes little at the normal ranges of pressure, but increases 
rapidly with the increasing pressure-up to a physiologic limit. It remains elevated and changes very little with intraluminal pressure above 100 and up to 200 $\mathrm{mmHg}$ [11-14].

The peculiar helical vorticeal pattern of flow inside the aorta causes this energy load to be exerted in three axes in the vascular wall: longitudinal, circumferential and radial. In addition, this pattern of streamlined helical flow leads to low shear stress at the endothelial level, causing the release of endothelial nitric oxide (eNO), which exerts positive remodeling effects on the vascular wall, promoting repair of the extracellular matrix components and their further maturation and organization. The impact of flow pattern on the wall stress and shear stress is crucial in understanding the genesis of different aortic disease processes. Most of the existing literature (and even textbooks) is based on older fluid dynamics studies rooted in the Windkessel model or the Poiseuille equation, where intraluminal flow is assumed to be linear, parallel coaxial flow along the longitudinal axis of the vessel, with a parabolic wavefront, with the highest velocity being at the center. Recent evidence from imaging and simulation studies has established the two-phase helical, vorticeal flow, where a vortex travels inside the vessel in a spiral fashion, with the direction of the twist reversed during diastole [15-17].

The end result of this flow-mediated homeostasis of the aortic wall is increased structural integrity and improved "flexibility" (deformability or compliance). In other words, the aorta becomes more able to withstand the energy load, distend in response to its application with each pulsation, and recoil back to its baseline dimensions afterwards without significant damage to its components [18].

Changes in any of the factors involved in these homeostatic mechanisms in the aortic wall (e.g., flow pattern, turbulence, endothelial dysfunction, genetic predisposition, signaling or transcriptional pathway anomalies, receptor disorders, extracellular matrix components, structural, or functional disorders, metabolic or toxic agents, etc.) (Table 1) will cause a shift of these mechanisms towards another pathway rather than the normal reparative one. Two alternate pathways are described:

1. A pathway where there is increased destruction, disorganization, weakening or malfunction of the tunica medica components without endothelial dysfunction, atherosclerotic or atherothrombotic processes. This results in decrease in the structural integrity and compliance of the vessel. Such aortas have a greater tendency to dilate, since their elastic recoil properties are decreased. As seen from the effects of lathyrism on animals, these vessels also are at a higher risk for spontaneous rupture (i.e., dissection) regardless of diameter.

2. Another pathway is mediated primarily by the endothelium, and the pathology is a pronounced chronic inflammatory process centered around the intima-media region, involving oxidative stress, lipid deposition and ultimately calcification. This is the classic atherothrombotic pathway (Figure 2).

Therefore, preservation of the structural integrity and elastic properties (i.e., wall stiffness and wall compliance) of the tunica media is far more significant, in terms of mechanical performance, than just the diameter. Time and again, surgeons have encountered dilated segments of the aorta without any evidence of structural wear or defect, while having to operate emergently on normal-sized aortas that have disintegrated because of their fragility. Several animal and human studies have documented dissection of normal-sized aortas upon exposure to certain substances (sometimes known as lathyrogens) [19].

\section{Dissection as a catastrophic structural failure:}

The aorta, in engineering terms, is designed to sustain a certain mechanical load in order to transfer a specific volume of blood per unit of time, while maintaining the blood volume inside the vessel at all times. A useful parallel of this process is the function of a fluid pipe, which must withstand the pressure of the fluid inside to safeguard its flow to its destination.

Aortic dissection is, therefore, a failure of the aortic wall to sustain the energy load that is applied to it with each heartbeat, allowing the blood to escape outside its lumen and-of course-impair its transport function. It is, thus, similar to the rupture of a water pipe, which is defined in civil engineering terms as "gross movement of major components of a 
Table 1. Factors influencing the composition and structural integrity of the aortic wall.

\begin{tabular}{|c|c|c|}
\hline (a) Aortic wall factors & (b) Blood Flow-Aortic Wall /interactions & (c) Patient Factors: \\
\hline Endothelial Function (intima) & Diameter (surface area) & Age \\
\hline Integrity & Resting intraluminal pressure & Growth phase \\
\hline Trauma & $\begin{array}{l}\text { Cyclic pressure change; total energy load; } \\
\text { energy loss }\end{array}$ & Growth hormone replacement \\
\hline Adhesion molecules (vCAM, VAP-1) & Heart rate (frequency of energy load) & Pro-apoptotic gene expression \\
\hline Endothelial nitric oxide & $\begin{array}{l}\text { Ventricular systolic function and ejection } \\
\text { (initial force generation) }\end{array}$ & VAP-1 \\
\hline Subintimal Extra-Cellular Matrix & $\begin{array}{l}\text { Aortic valve morphology and competence } \\
\text { (flow wave morphology) }\end{array}$ & Gender \\
\hline $\begin{array}{l}\text { Gene mutation, expression and } \\
\text { transcription }\end{array}$ & Blood volume & Sex-specific conditions \\
\hline Collagen content & Blood viscosity & $\begin{array}{l}\text { Gonadal function (endogenous sex } \\
\text { steroids) }\end{array}$ \\
\hline Collagen organization & $\begin{array}{l}\text { Humorally active blood components: } \\
\text { platelets, circulating macrophages }\end{array}$ & Hormonal replacement therapy \\
\hline Elastic Lamellae & $\begin{array}{l}\text { Integrity of elastin-fibrillin-smooth muscle } \\
\text { cell "scaffolding" structure }\end{array}$ & Estrogen and progesterone \\
\hline $\begin{array}{l}\text { Gene mutation, expression, and } \\
\text { transcription }\end{array}$ & Aortic stiffness ("Young's modulus") & Oral contraceptives \\
\hline Elastin content & Extent of mechano-trasduction: & Pregnancy and peripartum period \\
\hline $\begin{array}{l}\text { Elastin fiber organization and } \\
\text { maturation }\end{array}$ & Signaling pathways & Cardiovascular Risk Factors \\
\hline Integrity of fibrillin "bridges" & Downstream gene expression & Hypertension \\
\hline Vascular Smooth Muscle Cells & & Hyperlipidemia \\
\hline Differentiation & & Dyslipidemia \\
\hline $\begin{array}{l}\text { Gene mutation, expression and } \\
\text { transcription }\end{array}$ & & Diabetes mellitus \\
\hline Extracellular matrix regulatory function & & Renin-angiotensin-aldosterone activity \\
\hline Migration across elastic lamellae & & Chronic kidney disease \\
\hline Interaction with macrophages & & Systemic Factors \\
\hline Integrity of actin bridges & & ACE-I, ARB \\
\hline Myosin heavy chain $(\mathrm{MYH})$ integrity & & Vitamin deficiency \\
\hline Contractile function & & Copper deficiency \\
\hline Calcium turnover & & Vascular toxins \\
\hline TGF- $\beta$ & & Cocaine abuse \\
\hline Angiotensin receptor I & & Alcohol abuse \\
\hline Angiotensin receptor II & & Smoking \\
\hline \multicolumn{3}{|l|}{ Adventitia } \\
\hline \multicolumn{3}{|l|}{ Extracellular matrix components } \\
\hline \multicolumn{3}{|l|}{$\begin{array}{l}\text { Migration across elastic lamellae } \\
\text { fenestrations }\end{array}$} \\
\hline $\begin{array}{l}\text { Interaction with lymphocytes/macro- } \\
\text { phages }\end{array}$ & & \\
\hline
\end{tabular}




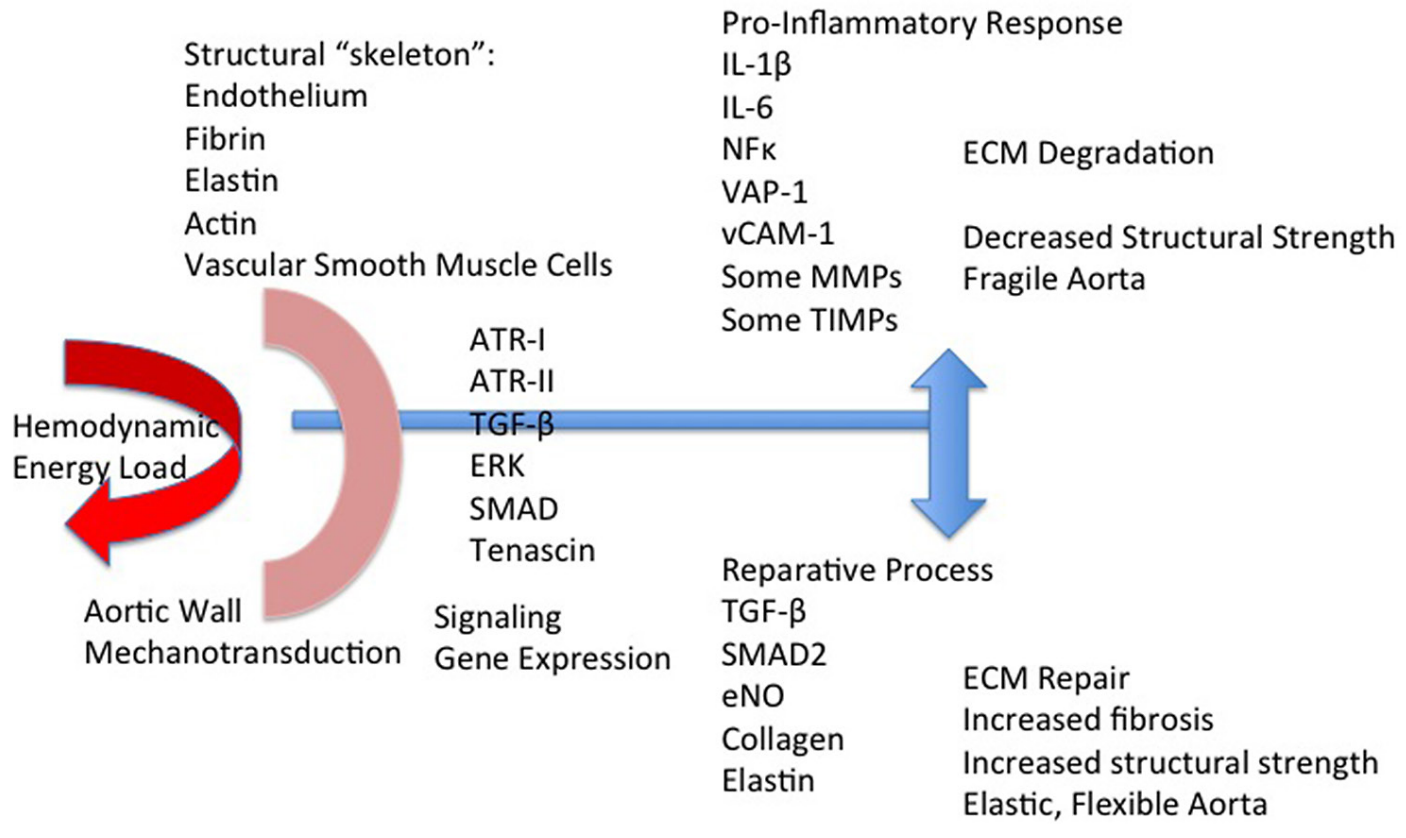

Figure 2. Graphic representation of the effect of the cyclic stretch on the two main opposing processes within the aortic wall.

structural system that renders them incapable of supporting the intended loading."

Since aortic dissection is a catastrophic structural failure, utilizing the principles of accident investigation may be a helpful approach towards understanding its genesis and, therefore, predicting the risk of its occurrence .

The first principle of any accident investigation is the definition of failure. The American Society of Civil Engineers' Council on Forensic Engineering [20] provides this simple yet comprehensive definition: "An unacceptable difference between the expected and observed performance." In other words, failure is a serious deviation from "what should happen" to "what should not happen." This echoes the often cited definition of an error by James Reason: "Occasion in which a planned sequence...fails to achieve its intended outcome" [21, 22].

The process to better understand the reason why and how failure occurs, leads us to the second principle of accident investigation: Root Cause analysis. Now established as a standard methodology in investigating accidents and errors in numerous fields, including manufacturing, industry, aviation and recently healthcare, this methodology aims at identifying the factor(s) directly responsible for causing the deviation from normal performance. In other words, identifying what caused the error to occur [23].

The fundamental first step in root cause analysis is a comprehensive understanding of "what should happen". This describes the Process Mapping; a procedure where the expected course and sequence of events is plotted on a central timeline from beginning to end, with every factor that is influencing this process plotted as a side arrow intersecting the process line central pathway at an angle. The process map has gained considerable popularity, as it provides a simple, systematic graphic representation of all the factors influencing the pathway and end-result of any given process. Graphically plotting the different factors involved in effecting a certain result permits us to more adequately evaluate the specific point where this anticipated effect did not take place, and for which reason. For instance, a missing or malfunctioning component in an assembled product can be traced to the point of its insertion and/or testing, 


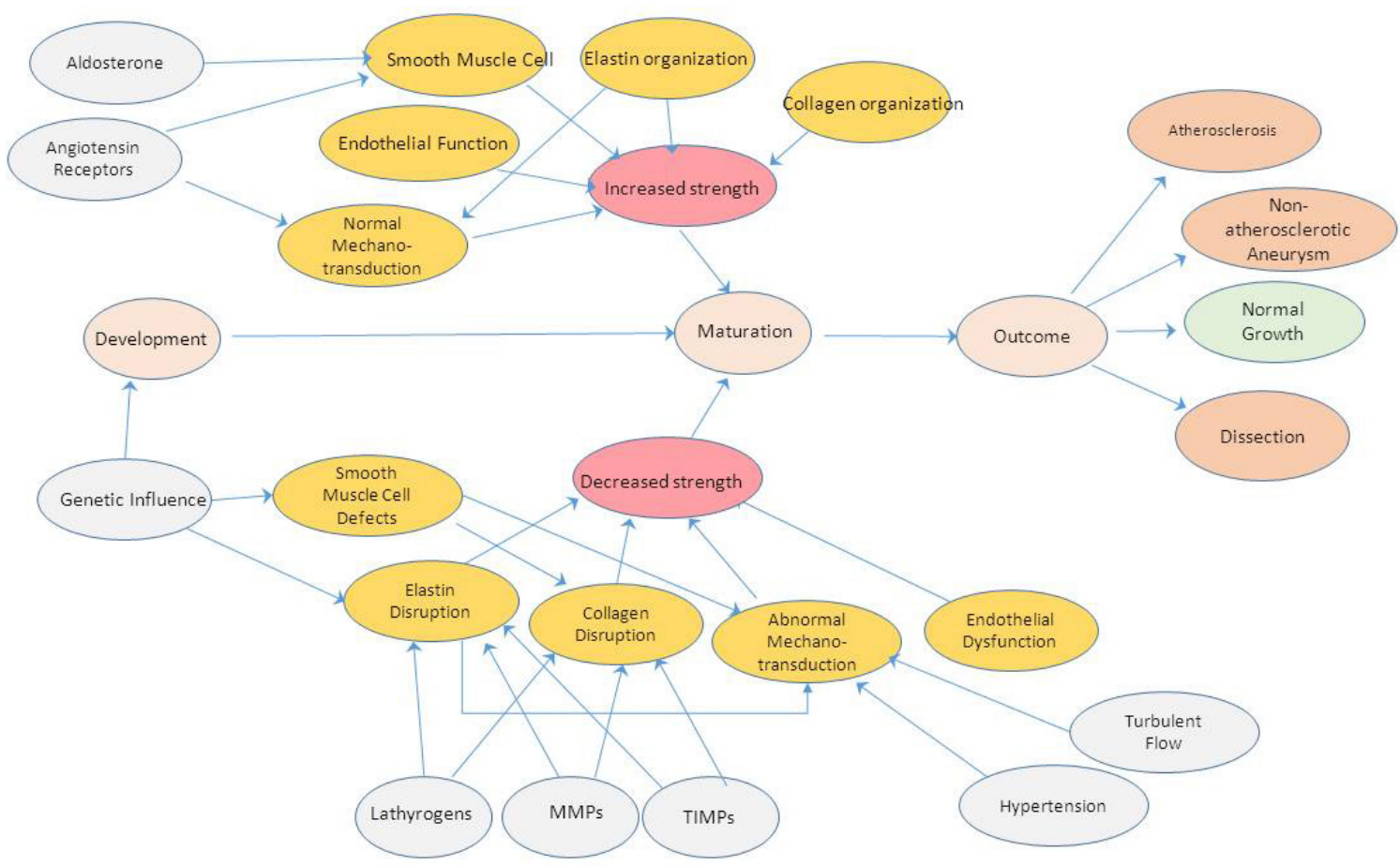

Figure 3. Simplified graphic representation of the process map for the aortic wall growth and maturation (main process line) with simplified depiction of some second- and third-order factors influencing the first-order factors and the net effect on the final outcome.

thereby identifying the "root cause" of the failure of that specific component. One well-publicized example of this has been the investigation of the O-rings in the space shuttle disaster by NASA.

The resulting Ishikawa diagram, after who first described it, is also commonly known as the "fishbone", "herringbone" or even "fishikawa" diagram and has become one of the Seven Basic Tools of Quality in any field (Figure 3). Because of its adaptability and room for expansion, it can be applied to simple as well as complex processes, making it a very versatile and widely applied tool [24-27]. One of the most important features of the Ishikawa model for process mapping is the ability to identify all factors impacting any given process, no matter how "insignificant" they might seem. Lessons from the NASA "Threat and Error Model" [28] and the "Swiss Cheese" model spotlight the importance of small deviations at points further away from the central process that precipitate an "unintended state" affecting the next several steps in the process. If the effect of these unintended states is not reversed or counterbalanced at earlier points in the process, the deviation is transmitted farther downstream, creating an "unintended state" which is further amplified by the other factors involved and ultimately causing a major deviation from the expected result. The failure to identify the seemingly insignificant detail of the temperature range change on the performance of the O-ring-for instance-has "snowballed" into the catastrophic structural failure in the space shuttle.

As described earlier, aortic dissection is a grave imbalance between two opposing forces: structural strength and energy load. These describe the two main processes impacting the aortic wall. These are akin to the tension and compression forces impacting the safety of a bridge. The energy load applied to the aortic wall with pulsatile flow is counteracted by the tension forces generated in the three axes within the aortic wall.

Thus, the process map for aortic dissection may be graphically represented by a central pathway impacted 


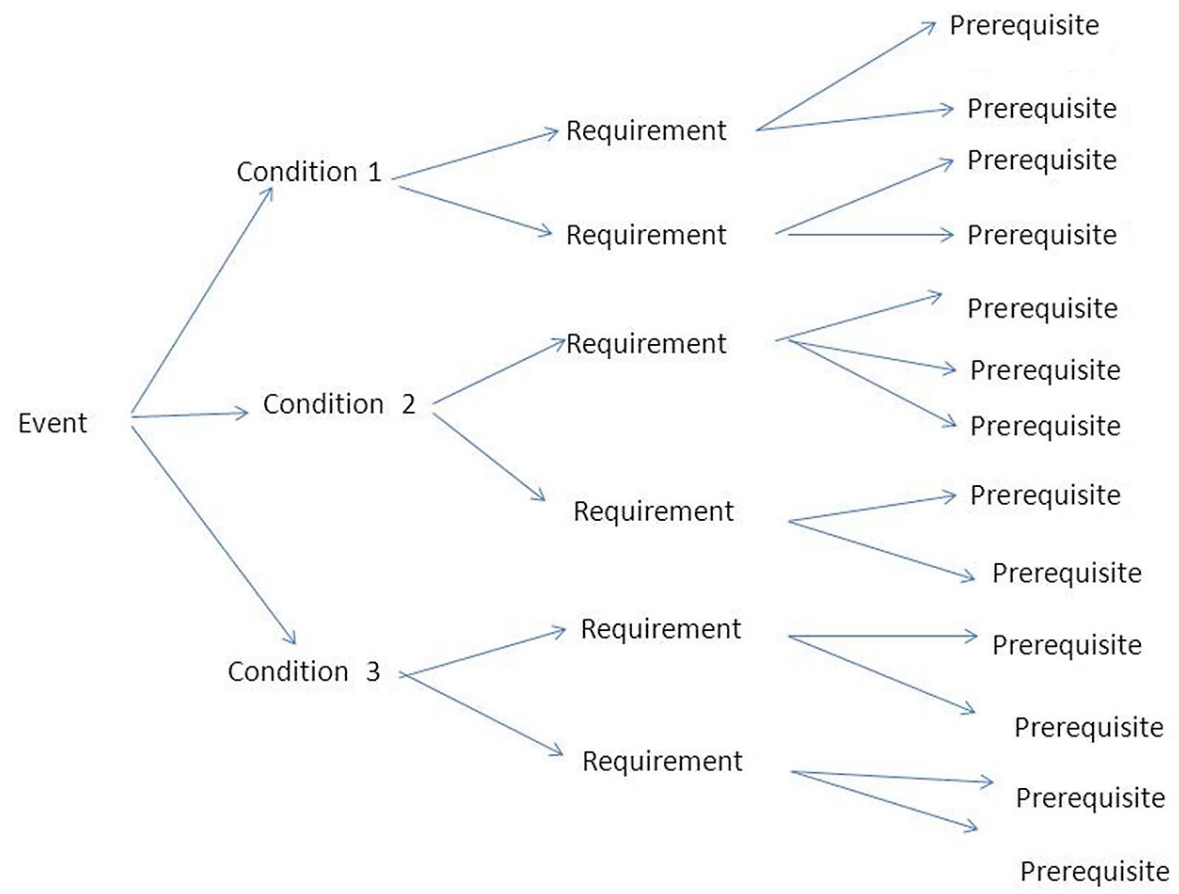

Figure 4. Graphic representation of a typical Bayesian conditional probability decision tree, the basis for developing probabilistic decision support tools. The probability of each event is dependent on the combined probabilities of the preceding factors, each in turn is the product of the combined probability of the preceding factors or prerequisites.

by two side arrows, one representing the structural integrity of the vessel wall, while the other represents the energy load applied to the aorta. This produces two intersecting and inter-dependent Ishikawa diagrams, because each of these two processes itself is dependent on multiple upstream factors (Figure 4).

Since each result in this diagram is dependent on a number of other conditions "upstream," the occurrence of one event (e.g., proper elastin organization) is dependent on the likelihood of the presence of some other factors (e.g., gene mutation, ligand activity, pharmacologic agents, etc.) This pattern of dependence describes an "Influence Diagram" of conditional probability. In such arrangement, the probability of one event is dependent on the presence of a number of antecedent events; each-in turn-is dependent on the presence of another set of prerequisites. The resulting arrangement is usually referred to as a Bayesian decision tree, where every event is dependent on the interaction of two or more preceding factors and/or events. Generally speaking, representing the probability of each condition is done either by a
Boolean assignment of value in terms of $1 / 0$ (i.e., true or false) or in terms of its probability of being true at the time of examination, that is, fractions of one or percentages.

\section{Guidelines and Decision-Making Methodology}

Over the centuries, the practice of medicine has evolved from a personality-based decision making model to an evidence-based, data-driven decision making model. Because of the increasing emphasis on patient safety and error prevention, practice guidelines have emerged in recent decades as decision support tools to ensure the identification of high-risk situations and the prompt and appropriate implementation of interventions to reduce the risk of death or harm to patients [30]. Consequently, and by definition, practice guidelines are predictive models based on risk stratification. Since risk is defined as the probability of an error or an accident, the implementation of a probabilistic approach to decision-making becomes more attractive. Drawing on principles 
of medical triage, the inclusion of a prognostic approach, stratifying the possible outcomes according to their expected severity and impact on survival and quality of life, becomes a much desirable feature of any comprehensive set of practice guidelines.

Since virtually all biologic systems are complex environments, involving numerous inter-dependent factors (many of which are unknown or poorly understood) exerting their influence in a complex, interconnected and highly variable pattern, the use of classic rule-based decision-making tools becomes inappropriate [31]. Rule-based decision making (e.g., IF X THEN Y) assumes that probability of dissection is entirely dependent on the probability of size; that is, $p(D)=p(s)$ :

- A high degree of predictability, where X will always be true all the time

- A high level of causality, dependence and linear relationship between $X$ and $Y$

- A high degree of certainty about the effect of $Y$ on $\mathrm{X}$

- A high degree of certainty that only $X$ is responsible for the issue being examined

The previous discussion is illustrative that these assumptions may be inappropriate in a complex environment such as the aorta [32]. Therefore, the simplistic rule-based decision-making dictating that "IF diameter is $6 \mathrm{~cm}$ THEN operate" does not take into account the influence of other factors contributing to the structural integrity of the vascular wall, such as collagen gene expression, ATR-1 receptor function and its impact on the vascular smooth muscle cell regulation of the extracellular matrix, the degree of collagen maturation and organization within the aortic media. Nor do they reflect the impact of the different flow patterns in trileaflet versus bicuspid aortic valves, for instance, on the location, degree and effect of energy load on the aortic wall. Similarly, there remain countless other unrecognized or poorly understood factors (such as chromosome $X$ gene functions, vascular adhesion protein- 1 function, impact of growth hormone and its interaction with other components of the vascular wall, specific properties of each segment of the aorta, etc.) which seem to have some degree of influence on the structural integrity of the vascular wall, based on observational and/or anecdotal reports.
Given the complex, variable inter-dependent patterns and high degree of unpredictability of these factors, the central question in developing a decision-making algorithm becomes "what is the probability of aortic dissection $\mathrm{p}(\mathrm{D})$ given factor 1 , and factor 2, and factor 3, etc.?" In other words, what is the probability of aortic dissection $\mathrm{D}$ given condition $\mathrm{C} 1, \mathrm{C2}, \mathrm{C} 3 \ldots \mathrm{Cn}$.

Mathematically speaking, this is a composite function where the probability of $D$ is dependent on the probabilities of $\mathrm{C1}, \mathrm{C2}, \mathrm{C3}$...Cn etc. [33-37]. The formula can be expressed as follows:

$$
\mathrm{p}[\mathrm{D}]=\mathrm{p}\left[\mathrm { C } 1 { } ^ { * } \mathrm { p } \left[\mathrm { C } 2 { } ^ { * } \mathrm { p } \left[\mathrm{C} 3{ }^{*} \ldots \mathrm{p}[\mathrm{Cn}]\right.\right.\right.
$$

The goal, then, becomes to be able to adequately solve this equation and properly assess the probability (i.e., risk) of aortic dissection in a specific patient. In other words, 'tailoring' the recommendations for management of aortic disease towards developing patient-specific guidelines, based on the calculated risk of the disease event versus the risk of surgery.

Expressed in clinical terms, the question becomes: What is the predicted likelihood (i.e., risk) of aortic dissection occurring in a 32-year-old infertile, diabetic female of a specific ethnic background, of normal height, with no history of smoking or illicit drug abuse, but has a history of pre-hypertension, mild skeletal problems with normal skin elasticity, bicuspid aortic valve and an aortic diameter of 4.7 at the mid-ascending segment, etc?.

\section{Conclusions}

The mission of the governing and regulatory bodies in medicine remains the promotion of scientifically sound practices to reduce harm from disease and injury as well as from medical practice. Based on this, practice guidelines are developed, circulated and their implementation encouraged toward these goals of promoting the safety of the public and the prevention of serious events in the course of their lives.

The primary objective for the guidelines for management of thoracic aortic disease appropriately remains the prevention of catastrophic events; namely aortic dissection or rupture. The assignment of a high-level recommendation requires a comparatively 
high level of confidence (i.e., a high index of suspicion) about the probability of an event to occur, as well as the severity of its impact. In some cases, these guidelines have relied on a limited set of data (the socalled Expert Opinion) which has been derived from anecdotal evidence, limited observational studies or "personal experience" to develop high-level recommendations for clinicians. Given the gravity of the event and its serious impact on the survival, quality of life and healthcare resource allocations, the current discrepancy between the level of evidence and the level of recommendation calls for an improvement of the derivation of the clinical guidelines and an opportunity to better quantify "clinical experience" or "clinical sense."

Because of their suitability to offer a more comprehensive prediction of the conditional probability of a specific event, and also having the capability for developing a hierarchy of prognostic triage levels based on the expected outcomes, probability-based bioinformatics tools, rooted in the Bayesian principle [37-38], can offer a useful, dynamic and adaptable platform for developing such improved guidelines.

The challenge in designing and implementing such predictive models remains the categorization and classification of data sets; optimally national, longitudinal disease-specific data sets. Transdisciplinary collaboration is crucial for acquisition of such large, diverse and comprehensive data sets. Given the nature of the clinical problem, randomized controlled studies are not feasible; and standard statistical methodology is severely limited. However, careful analysis of observational data can yield important insight into the probability of such catastrophic events.
The development of a specific, dedicated inter-societal task force for a more comprehensive study of the outcomes of different strategies for atrial fibrillation ablation has established a most commendable example. Establishing a national registry incorporating all miniature details of the patient characteristics, disease course characteristics as well as procedural details has provided us with an invaluable and huge data set for robust analysis.

Large data repositories such as national registries, society registries, disease-specific registries and electronic medical records do hold a considerable promise for robust data gathering, which will be conducive to a more comprehensive predictive analysis and modeling. This holds the promise of providing a more adequate prediction of the risk for aortic dissection and hence a better tailoring of the diagnostic and therapeutic recommendations for such patients.

\section{Acknowledgements}

The author remains deeply appreciative to Professor Debora Simmons, PhD, RN and Krisanne Graves, $\mathrm{PhD}, \mathrm{RN}$ for their invaluable introduction to the science of safety.

\section{Conflict of Interest}

The author holds a full United States Patent for a Total Aortic Arch Reconstruction Graft. There are no financial disclosures.

\section{Comment on this Article or Ask a Question}

\section{References}

1. Lemaire S, Russell L. Epidemiology of thoracic aortic dissection. Nat Rev Cardiol. 2011;8:103-113. DOI: 10.1038/nrcardio.2010.187

2. Hiratzka LF, Bakris GL, Beckman JA, Bersin RM, Carr VF, Casey DE, Jr., et al. 2010 ACCF/ AHA/AATS/ACR/ASA/SCA/SCAI/SIR/STS/ SVM guidelines for the diagnosis and management of patients with Thoracic Aortic Disease: a report of the American College of Cardiology Foundation/American Heart Association Task Force on Practice Guidelines, American Association for
Thoracic Surgery, American College of Radiology, American Stroke Association, Society of Cardiovascular Anesthesiologists, Society for Cardiovascular Angiography and Interventions, Society of Interventional Radiology, Society of Thoracic Surgeons, and Society for Vascular Medicine. Circulation. 2010;121:e266-369, DOI: 10.1161/CIR.0b013e3181d4739e

3. Hagan $P$, Russman $C$, Isselbacher E, Bruckman D, Karavite D, Russman P, et al. The International Registry of aortic dissection (IRAD): New insights into an old disease.
JAMA. 2000;283:897-903. DOI: 10.1001/ jama.283.7.897

4. Criado FJ. Aortic dissection. A 250 year perspective. Tex Heart Inst J. 2011;38:694-700. PMID: 22199439.

5. Leonard J. Thomas Bevill Peacock and the early history of dissecting aneurysm. Br Med J. 1979;2:260-262. DOI: 10.1136/ bmj.2.6184.260

6. Sherif, HMF. Heterogeneity in the segmental development of the aortic tree: Impact on management of genetically triggered aortic aneurysms. 
Aorta (Stamford). 2014;2:186-195. DOI: 10.12945/j.aorta.2014.14-032

7. Wolinsky H, Glagov S. Structural basis for the static mechanical properties of the aortic media. Circ Res. 1964;14:400-413. DOI: 10.1161/01.RES.14.5.400

8. Milewicz D. Perturbation of the VSMC contractile unit and aortic aneurysm: Clinical presentation, incidence and mechanism. Proceedings, the Aortic Disease Summit. Baltimore, Maryland. September 22-23, 2009.

9. Sherif $\mathrm{H}$. In search of a new therapeutic target for the treatment of genetically triggered thoracic aortic aneurysms and cardiovascular conditions: Insights from human and animal lathyrism. Interact Cardiovasc Thorac Surg. 2010;11:271-276. DOI: 10.1510/icvts.2010.239681

10. Bonventre M. Sweet peas, copper, pregnancy and pills: Effects on the aorta. N Y State J Med. 1974;74:633-637. PMID: 4523429

11. Hahn C, Schwartz M. Mechanotransduction in vascular physiology and atherogenesis. Nat Rev Mol Cell Biol. 2009;10:53-62. DOI: 10.1038/nrm2596

12. Chung J, Lachapalle K, Wener E, Cartier R, De Varennes B, Fraser R, et al. Energy loss, a novel biomechanical parameter, correlates with aortic aneurysm size and histopathology. J Thorac Cardiovasc Surg. 2014;148:1082-1089. DOI: 10.1016/ j.jtcvs.2014.06.021

13. Hsieh H, Liu C, Huang B, Tseng A, Wang D. Shear-induced endothelial mechanotransduction: The interplay between reactive oxygen species (ROS) and nitric oxide (NO) and the pathophysiological implications. J Biomed Sci. 2014;21:3. DOI: 10.1186/1423-0127-21-3

14. Lu D, Kassab G. Role of shear stress and stretch in vascular mechanobiology. J R Soc Interface. 2011;8:1379-1385. DOI: 10.1098/rsif.2011.0177

15. Ando J, Yamamoto K. Vascular mechanobiology. Endothelial cell responses to fluid shear stress. Circ J. 2009;73:1983-1992. DOI: 10.1253/circj.CJ-09-0583

16. Cunningham A, Gotlieb A. The role of shear stress in the pathogenesis of atherosclerosis. Lab Invest. 2005;85:9-23. DOI: 10.1038/ labinvest. 3700215

17. Parker K. A brief history of arterial wave mechanics. Med Biol Eng Comput. 2009;47:111118. DOI: 10.1007/s11517-009-0440-5

18. Cavalcante J, Lima J, Redheuil A, Al-Mallah M. Aortic stiffness. J Am Coll Cardiol. 2011;57:1511-1522. DOI: 10.1016/j. jacc.2010.12.017
19. Sherif HMF. In search of a new therapeutic target for the treatment of genetically triggered thoracic aortic aneurysms and cardiovascular conditions: Insights from human and animal lathyrism. Interact Cardiovasc Thorac Surg. 2010;11:271-276. DOI: $10.1510 /$ icvts.2010.239681

20. Carper KL. Technical Council on Forensic Engineering: Twenty-year retrospective review. Foren Eng; 2003. p. 280-296. DOI: 10.1061/40692(241)29

21. Cavalcante J, Lima J, Redheuil A, AlMallah M. Aortic stiffness. J Am Coll Cardiol. 2011;57:1511-1522. DOI: 10.1016/ j.jacc.2010.12.017

22. Carper KL. Technical Council on Forensic Engineering: Twenty-year retrospective review. Foren Eng; 2003. p. 280-296. DOI: 10.1061/40692(241)29

23. Reason J. Human error. Cambridge, UK: Cambridge University Press; 1999. PMCID: PMC1070929

24. Gerstein M. Flirting with disaster: Why accidents are rarely accidental. New York: Union Square Press; 2008.

25. Accident investigation. Washington DC: U.S. Department of Labor, Occupational Safety \& Health Administration; 2002 [cited 2014 Sept 20]. Available at https://www. osha.gov/SLTC/accidentinvestigation/ investigations.html.

26. Tague NR. Seven basic quality tools. In: The Quality Toolbox. Milwaukee, Wisconsin: American Society for Quality; 2004, p. 15.

27. Ishikawa K Introduction to Quality Control. London: Chapman \& Hall; 1990, p. 448.

28. How to use the fishbone tool for root cause analysis. Center for Medicare and Medicaid Services [cited 2014 Sept 20]. Available at http://www.cms.gov/Medicare/Provider-Enrollment-and-Certification/QAPI/ downloads/FishboneRevised.pdf.

29. Dhandapani D. Applying the Fishbone diagram and Pareto principle to Domino. IBM Lotus technical library. June 2004 [cited 2014 Sept 20]. Available at http://www.ibm.com/ developerworks/lotus/library/fishbone/

30. Gunther D. Threat and error management. Emergency/Abnormal situations and security. San Jose, CA: NASA Ames Research Center; June 11-13, 2013 [cited 2014 Sept 20]. Available at http://humansystems.arc. nasa.gov/flightcognition/download/EAS_ Symposium_Presentations/Security.pdf.

31. Browne L. Regulation of professions by the state. the right to regulate, reasons therefore, methods in use, and attitude of regulatory bodies and the courts, with relation thereto. Cal West Med. 1935;43:119-123. PMID: 18743337.
32. Garoupa N. Regulation of professions in the US and Europe: A comparative analysis. Proceedings of the American Law and Economic Association Meetings. The Berkeley Electronic Press; 2004 [cited 2014 Sept 20]. Available at http://law.bepress. $\mathrm{com} / \mathrm{cgi} /$ viewcontent.cgi?article $=1053 \&$ context=alea.

33. Sherif $H$. Is practicing medicine virtually impossible? Employing virtual medicine technologies and techniques can help propel healthcare into the future. Healthc Inform. 2006;54-55. PMID: 16948337.

34. Rizzo J, Chen J, Fang H, Ziganshin BA, Elefteriades J. Statistical challenges in identifying risk factors for aortic disease. Aorta (Stamford). 2014;2:45-55. DOI: 10.12945/ j.aorta.2014.14-019

35. North DW. A tutorial introduction to decision theory. IEEE Trans Syst Sci Cyber. 1968;4:200-210. DOI: 10.1109/TSSC. 1968.300114

36. Bayesian networks and decision making. University of Waterloo, Canada [cited 2014 Sept 20]. Available at http://pami.uwaterloo.ca/ basir/ECE457/week10.pdf.

37. Lucas P. Bayesian networks in medicine: A model-based approach to medical decision making. In: Adlassnig KP. Proceedings of the EUNITE workshop on Intelligent Systems in Patient Care, Vienna. Vienna: Austrian Computer Society; 2001, p. 73-97.

38. Lucas $P$, Hommersom A. Modeling the interactions between discrete and continuous causal factors in Bayesian networks. In: Myllymki P, Roos T, Jaakkola T. Proceedings of the Fifth European Workshop on Probabilistic Graphical Models (PGM-2010). Helsinki: HIIT Publications; 2010, p. 185-193.

39. Sherif H., Sadeghi S, Mogel G. Design and construction of a computer-based logical system for medical diagnosis. IOS Press. 2001; 81:459-464. DOI: 10.3233/978-160750-925-7-459

40. Sherif HMF, Johnson SS, Klair SA. Implementation of a computer-based decision support system for outcomes prediction and clinical triage: Initial results of two pilot studies. J Cardiol Ther. 2013;1:71-77. DOI: 10.12970/2311-052X.2013.01.02.6

Cite this article as: Sherif HMF. Dissecting the Dissection: Towards More Comprehensive DecisionMaking Methodology for Thoracic Aortic Disease. AORTA (Stamford). 2015;3(3):108-117. DOI: http://dx.doi. org/10.12945/j.aorta.2015.14.060 